\title{
State Power in Ancient China and Rome, ed. W. Scheidel, Oxford 2015 (Oxford Studies in Early Empire), ss. 303*
}

Choć w pracach historyków porównywanie państw starożytnych z tymi współczesnymi nie jest niczym nowym, to $\mathrm{w}$ ostatnim czasie badania komparatystyczne nad antycznymi imperiami przeżywają swój zdecydowany rozkwit. Nierzadko ma to związek z kontekstem bieżącej sytuacji geopolitycznej. Phiroze Vasunia zauważył, że istnieje bezpośrednia zależność między nasileniem się interwencji zbrojnych prowadzonych po 2001 r. przez Stany Zjednoczone a wzrostem naukowego zainteresowania histo- rią imperiów od starożytności po czasy współczesne ${ }^{1}$. Podobnie przez pryzmat boomu gospodarczego Chin i ich rywalizacji geopolitycznej z USA należy postrzegać studia z 2008 i 2009, których przedmiotem było porównanie dwóch największych imperiów świata starożytnego - Cesarstwa chińskiego i rzymskiego ${ }^{2}$. W pracach tych po raz pierwszy $\mathrm{w}$ tak gruntowny sposób potraktowano problematykę podobieństw i różnic między tymi dwoma imperiami ${ }^{3}$. Wcześniejsze studia porównawcze nad starożytnymi Chinami i światem śródziem2014).

* Publikacja powstała przy wsparciu finansowym Fundacji na Rzecz Nauki Polskiej (stypendium START

${ }^{1}$ P. Vasunia, The Comparative Studies of Empires, „Journal of Roman Studies” 2011, 101, s.222. Vasunia stwierdził również, że artykuł P. A. Brunta Reflections of British and Roman imperialism, „Comparative Studies in Society and History" 1964/1965, 7, s. 267-288, wskazuje nie tylko na autorskie zainteresowanie antykiem, lecz także procesem dekolonizacyjnym, który nastąpił na świecie po II wojnie światowej.

${ }^{2}$ Conceiving the Empire: China and Rome Compared, ed. F.-H. Mutschler, A. Mittag, Oxford 2008; Rome and China. Comparative Perspectives on Ancient World Empires, ed. W. Scheidel, Oxford 2009. Mniej więcej w tym samym czasie ukazała się także praca V. Smila, Why America is not a new Rome, Cambridge-Massachusetts-London 2010.

${ }^{3}$ Tematem przewodnim wcześniejszych studiów (głównie artykułów) poświęconych historii starożytnego Rzymu i Chin była przede wszystkim tradycja historiograficzna. Zob. np. F.-H. Mutschler, Vergleichende Beobachtungen zur griechisch-römischen und altchinesischen Geschichtsschreibung, „Saeculum” 1997, 48, s. 213-253; idem, Tacitus und Sima Qian: Persönliche Erfahrung und historiographische Perspektive, „Philologus" 2007, 151, s. 127-152. 
nomorskim wchodziły $\mathrm{w}$ zakres historii intelektualnej i obejmowały głównie dokonania starożytnych Chińczyków i Greków w zakresie kultury i myśli naukowej ${ }^{4}$.

Studium komparatystyczne nad Cesarstwem chińskim i rzymskim, które ukazało się w 2009 r. pod redakcją cenionego badacza historii społecznej i ekonomicznej starożytnego Rzymu, profesora historii starożytnej na Uniwersytecie Stanforda Waltera Scheidela, dotyczyło z kolei innej problematyki ${ }^{5}$. Autorzy poszczególnych rozdziałów podejmowali zagadnienia $\mathrm{z}$ zakresu historii politycznej, społecznej, wojskowej oraz ekonomicznej. Sporo miejsca poświęcono także rozwiązaniom prawnym, które obowiązywały w obu imperiach. Studia te nie wyczerpały jednak podjętej problematyki. Recenzowaną pracę z pewnością należy postrzegać jako ich kontynuację, zwłaszcza w kontekście instytucjonalnej, państwowotwórczej struktury obu państw starożytnych. W 2015 r. nakładem Oxford University Press pod redakcją W. Scheidela ukazała się monografia State Power in Ancient China and Rome jako kolejny tom z serii Oxford Studies in Early Empires ${ }^{6}$. Sześć $\mathrm{z}$ ośmiu prezentowanych $\mathrm{w}$ tym tomie rozdziałów stanowi pokłosie konferencji State Power and Social Control in Ancient China and Rome, zorganizowanej na Uniwersytecie Stanforda w dniach 17-19 marca 2008 r. w ramach projektu Stanford Ancient Chinese and Mediterranean Empires Comparative History Project.

Celowość prowadzenia badań porównawczych i interdyscyplinarnych (czy raczej transdyscyplinarnych) dotyczących podjętej $\mathrm{w}$ recenzowanej publikacji problematyki ma silne podstawy. Zdaniem W. Scheidela perspektywa komparatystyczna w badaniach nad starożytnymi imperiami jest wyjątkowo owocna poznawczo. Pozwala bowiem wyszczególnić i zdefiniować najważniejsze problemy badawcze, jak również postawić wiele nowych pytań, które dotąd nie funkcjonowały w dyskursie naukowym, zdominowanym przez wyspecjalizowane studia historyczne ${ }^{7}$. Ponadto zestawianie historii Chin i Rzymu na zasadzie case studies rzuca światło na fenomen funkcjonowania tych dwóch imperiów. Stwarza to szansę zarówno dostrzeżenia podobieństw oraz różnic między tak odmiennymi formacjami kulturowymi, jak również otwiera pole do porównania ich ze współczesnym światem, w którym bardzo ważną rolę gospodarczą i polityczną odgrywają Chiny ${ }^{8}$.

Samą ideę podejmowania studiów porównawczych nad starożytnymi Chinami i Rzymem należy uznać za jak najbardziej zasadna, przede wszystkim ze względu na niektóre uwarunkowania historyczne łączące oba opisywane państwa. Wzajemne zależności między historią Cesarstwa

\footnotetext{
${ }^{4}$ Zob np. G. E. R. Lloyd, Adversaries and Authorities: Investigations into Ancient Greek and Chinese Science, Cambridge 1996; G. E. R. Lloyd, N. Sivin, The Way and the Word: Science and Medicine in Early China and Greece, New Haven 2002; G. E. R. Lloyd, Ancient Worlds, Modern Reflections: Philosophical Perspectives on Greek and Chinese Science and Culture, Oxford 2004. Por. J. Tanner, Ancient Greece, Early China: SinoHellenic Studies and Comparative Approaches to the Classical World: A Review Article, „Journal of Hellenic Studies" 2009, 129, s. 89-109.

${ }^{5}$ Rome and China. Comparative Perspectives on Ancient World Empires, ed. W. Scheidel, Oxford 2009.

${ }^{6} \mathrm{~W}$ dorobku naukowym W. Scheidela znajdują się także inne prace dotyczące problematyki komparatystycznego i często transdyscyplinarnego ujęcia historii państw świata starożytnego. Zob. np. The Dynamics of Ancient Empires: State Power from Assyria to Byzantium, ed. I. Morris, W. Scheidel, Oxford 2010; The Oxford Handbook of the State in the Ancient Near East and Mediterranean, ed. P. F. Bang, W. Scheidel, Oxford 2013; Fiscal Regimes and the Political Economy of Premodern States, ed. A. Monson, W. Scheidel, Cambridge 2015.

${ }^{7}$ W. Scheidel, Introduction, [w:] State Power..., s.4: [...] a comparative perspective offers a much-needed antidote to hyperspecialization, a bane of contemporary professional historiography.

${ }^{8}$ Niedawno starano się także porównać system polityczny Cesarstwa rzymskiego i Korei Północnej. Zob. J. A. Rosenblitt, Rome and North Corea: Totalitarian Questions, „Greece and Rome” 2012, 59, s. $202-213$.
} 
chińskiego i rzymskiego zwykło się prezentować w literaturze przedmiotu jako przejście od - jak sformułował to $W$. Scheidel - „Great Convergence”, która obejmowała 1000 lat p.n.e. i pierwsze 500 lat n.e., aż do „First Great Divergence”, która nastąpiła w VI w. n.e. ${ }^{9} \mathrm{Na}$ przełomie er (Chiny - dynastia Qin/Han 221 r. p.n.e. 220 r. n.e.; Rzym - ok. 220 r. p.n.e. -395 r. n.e.) Cesarstwo chińskie oraz rzymskie, ogarniające wówczas zachodnią i wschodnią część Eurazji, tworzyły zupełnie niezależnie od siebie - co podkreślają autorzy - dwa silne organizmy polityczne, które, choć zajmowały jedynie niewielką część powierzchni Ziemi, to obejmowały prawdopodobnie połowę światowej populacji. Te dwa państwa, rządzone przez cesarzy i dysponujące armiami liczącymi setki tysięcy żołnierzy, istniały dłużej niż większość „pre-modern imperial states”. Ponadto zarówno Rzym, jak i Chiny, jako państwa „uniwersalne”, pretendowały do tego, by władać całym ówcześnie znanym światem (koncepcje orbis terrarum i tianxia), a przy tym strzegły swych granic przed najazdami „barbarzyńców” (limes i Wielki Mur Chiński).

Autorami rozdziałów recenzowanej monografii jest międzynarodowe grono badaczy (nie tylko historyków, ale także socjologów), zajmujących się historią obu cywilizacji, co - zgodnie z zamysłem projektu - miało służyć zaprezentowaniu podjętej problematyki w szerokiej i złożonej perspektywie. Po wstępie przygotowanym przez redaktora $W$. Scheidela $\mathrm{w}$ pierwszym rozdziale Kingship and Elite Formation Peter Fibiger Bang i Karen Turner, biorąc na warsztat przede wszystkim rządy dynastii Han i pryncypat Oktawiana Augusta, przeanalizowali relacje władzy między cesarzami i elitami w obu imperiach. Zaprezentowali także rozważania nad koncepcjami (typami idealnymi) arystokratyczne- go charakteru rządzących elit rzymskich z jednej strony i kadrami biurokratycznymi wywodzącymi się ze społeczeństwa chińskiego z drugiej. Autorzy starali się przedstawić wspólne dla obu państw starożytnych cechy administracji (m. in. działalność niewolników, wyzwoleńców i eunuchów na dworach cesarskich) oraz podobieństwa $\mathrm{w}$ zakresie struktur władzy czy kształtowania się elit. Odwołując się m. in. do koncepcji Norberta Eliasa (18971990), omówili również funkcjonowanie dworów cesarskich w Rzymie i Chinach, jak też charakter relacji między nimi a arystokracją. Bang i Turner zwrócili ponadto uwagę na pewne różnice $\mathrm{w}$ funkcjonowaniu obu administracji, podkreślając na przykład, że sposób wyłaniania się lokalnej (prowincjonalnej) elity administracyjnej w Chinach miał charakter bardziej scentralizowany niż w przypadku rzymskich, w większości śródziemnomorskich, „miast-państw". W kolejnym rozdziale Toward a Comparative Understanding of the Executive Decision-Making Process in China and Rome T. Corey Brennan, koncentrując się na problemie z zakresu historii komunikacji, zajął się analizą procesu podejmowania decyzji w starożytnym Rzymie i Chinach okresu dynastii Han. Zauważył, że w obu tych państwach ważną rolę $\mathrm{w}$ procesie decyzyjnym odgrywały rady cesarskie $\mathrm{w}$ postaci urzędnika lub grupy urzędników (ministrów). W przeciwieństwie do consilium, funkcjonującego przy cesarzu rzymskim, cesarz z dynastii Han nie brał udziału w naradach swoich ministrów-ekspertów. W rozdziale trzecim i czwartym zaprezentowano problematykę funkcjonowania obu państw antycznych $\mathrm{w}$ ramach administracyjnych struktur biurokratycznych, która jak się wydaje - jest zasadnicza dla zrozumienia fenomenu systemu władzy w obu imperiach. W rozdziale The Han Bureaucracy. Its Origin, Nature and Development Din-

\footnotetext{
${ }^{9}$ W. Scheidel, From the "Great Convergence" to the "First Great Divergence:" Roman and Qin Han State Formation and its Aftermath, [w:] Rome and China..., s.12.
} 
gxin Zhao omówił struktury biurokracji w Cesarstwie chińskim oraz ich hierarchię jak również sposób rekrutowania urzędników. W swych rozważaniach Zhao odwołał się do kryteriów typu idealnego biurokracji, sformułowanych niegdyś przez Maxa Webera (1864-1920). Stwierdził przy tym, że żadna $\mathrm{z}$ "premodern bureaucracy” nie może w sposób pełny odzwierciedlać kryteriów Webera, gdyż te opierały się na założeniach charakterystycznych dla biurokracji nowożytnych i współczesnych. Ponadto wzorcowy model Webera nie miał oddawać rzeczywistości empirycznej. Zhao wyliczył, że kształtowana stopniowo administracja chińska, która narodziła się w czasach dynastii Han, liczyła ponad 120 tysięcy urzędników i pod wieloma względami przypominała strukturę biurokratyczną. Przywołując ustalenia socjologów, badacz ten uznał, że prowadzenie działań zbrojnych stanowiło ważny czynnik stymulujący wzrost biurokracji w Chinach. Autor stwierdził, że funkcja stojącego na czele biurokracji cesarza chińskiego, w przeciwieństwie do władcy rzymskiego, była bardziej rytualna i pasywna. Dużą rolę w biurokracji dynastii Han, która - zdaniem Zhao - ukształtowała się za rządów cesarza Wu (141-87 p.n.e.), odgrywał natomiast sekretariat kanclerza, podzielony na trzynaście różnych, wyspecjalizowanych w określonej dziedzinie, biur. Według autora ideowe podstawy biurokracji chińskiej (swego rodzaju "bureaucratic ideology"), których istnienia nie da się potwierdzić w Cesarstwie rzymskim, wiązać należy z dominująca rolą konfucjanizmu.

W najdłuższym rozdziale (s. 90-149) The Common Denominator. Late Roman Imperial Bureaucracy from a Comparative Perspective Peter Eich zbadał administrację rzymską przez pryzmat koncepcji biurokracji i, podobnie jak Zhao, zauważył nieprzystawalność kryteriów Webera do realiów administracji rzymskiej. Eich stwierdził, że gdyby badać ten problem przez pryzmat koncepcji biurokratycznych (zwłaszcza legalnej i racjonalnej) niemieckiego socjologa, to należałoby uznać, iż w cesarskim Rzymie biurokracja nigdy nie funkcjonowała. W omawianym rozdziale w kontekście administracji Cesarstwa rzymskiego pisze się raczej o "protobureaucratic administration" w szerszym ujęciu patrymonialnym. Według Eicha administracja rzymska okresu republikańskiego nie posiadała żadnych cech biurokracji. Najważniejszym elementem systemu władzy w tym czasie była armia i prowadzone przez nią wojny, nie zaś trwałe i zorganizowane rozwiązania instytucjonalne. Wprawdzie w okresie wczesnego pryncypatu można dostrzec pewne elementy zorganizowanej administracji (funkcjonowanie ekwickich prokuratorów i prefektów), jednak nie świadczą one o działalności biurokracji sensu stricto. Proces biurokratyzacji administracji rzymskiej - zdaniem Eicha - miał się rozpoczać pod koniec II w. n.e. za panowania Sewerów i był kontynuowany w okresie późnego Cesarstwa. Właśnie administrację $\mathrm{z}$ okresu późnego Cesarstwa Eich porównał $\mathrm{z}$ biurokracją chińską z okresu dynastii Han. Autor wyraźnie podkreślił, że abstrakcyjne reguły właściwe nowożytnym biurokracjom nigdy w Cesarstwie rzymskim nie istniały, podstawową zasadą organizującą działalność urzędników była wola cesarska.

W. Scheidel w tekście State Revenue and Expenditure in the Han and Roman Empires, posługując się licznymi danymi statystycznymi, szczegółowo omówił zagadnienie funkcjonowania struktur fiskalnych („fiscal sceletons") odpowiedzialnych za państwowe dochody i wydatki. Kwestia ta wydaje się szczególnie istotna, ponieważ ważnym zadaniem obu państw był sprawny pobór podatków, z których pokrywano ogromne koszty związane $\mathrm{z}$ utrzymaniem armii i funkcjonowaniem urzędników. Autor ostrożnie skonstatował, że w Cesarstwie rzymskim największe wydatki wiązały się z utrzymaniem armii, w Chinach zaś najbardziej kosztochłonna była biuro- 
kracja. Kolejne dwa rozdziały monografii dotyczyły zagadnień urbanizacyjnych. W tekście Urban Systems in the Han and Roman Empires. State Power and Social Control Carlos Noreña zbadał zmiany zachodzące $\mathrm{w}$ "systemie miejskim" ( $\mathrm{w}$ tym proces urbanizacji) w obu państwach, jak również to, na ile miasta były efektywnym instrumentem realizacji polityki państwowej, $\mathrm{m}$. in. w zakresie kontroli społecznej. Autor za ważną cechę miast w Cesarstwie rzymskim uznał autonomię elit miejskich, wyraźnie kontrastującą z kontrolą władz chińskich, która rozciągała się nad miastami w państwie dynastii Han. Kontynuację tematyczną tego tekstu stanowi kolejny rozdział Public Spaces in Cities in the Roman and Han Empires, w którym Mark Edward Lewis skupił się na analizie podobieństw i przede wszystkim różnic w funkcjonowaniu sfery publicznej oraz miejskiej przestrzeni publicznej (m. in. symboliczne i ideologiczne funkcje budowli) w obu imperiach na przykładzie stolic (Rzymu w Imperium Romanum oraz Xianyang, Chang'an i Luoyang w Cesarstwie chińskim), jak i miast prowincjonalnych (regionalnych). W ostatnim rozdziale Ghosts, Gods, and the Coming Apocalypse. Empire and Religion in Early China and Ancient Rome, będącym studium z zakresu "teologii politycznej”, Michael Puett przybliżył problematykę aspektów religijnych oraz politycznych władzy cesarskiej w Chinach i Rzymie. Skupił się przy tym na analizie genezy statusu (kultu) boskiego władców rzymskich i chińskich, a także jego znaczeniu. Puett wskazywał na pierwszych ubóstwionych władców w osobach cesarza Wu i Juliusza Cezara.

Recenzowana praca z pewnością stanowi całkowite novum w literaturze naukowej. Wraz z monografią Rome and China. Comparative Perspectives on Ancient World Empires z 2009 r. składa się na wieloaspektowe i transdyscyplinarne studium, które ukazuje Cesarstwo chińskie oraz rzymskie w nowym świetle oraz pozwala w większym stopniu zrozumieć fenomen długo- trwałego funkcjonowania tych dwóch imperiów antycznych.

$$
\begin{array}{r}
\text { Karol Kłodziński (Toruń) } \\
\text { cezar871@wp.pl }
\end{array}
$$

\section{BIBLIOGRAFIA:}

Brunt P. A., Reflections of British and Roman imperialism, "Comparative Studies in Society and History" 1964/1965, 7.

Conceiving the Empire: China and Rome Compared, ed. F. H. Mutschler, A. Mittag, Oxford 2008.

Fiscal Regimes and the Political Economy of Premodern States, ed. A. Monson, W. Scheidel, Cambridge 2015.

Lloyd G. E. R., Adversaries and Authorities: Investigations into Ancient Greek and Chinese Science, Cambridge 1996.

Lloyd G. E. R., Ancient Worlds, Modern Reflections: Philosophical Perspectives on Greek and Chinese Science and Culture, Oxford 2004.

Lloyd G. E. R., Sivin N., The Way and the Word: Science and Medicine in Early China and Greece, New Haven 2002.

Mutschler F. H., Vergleichende Beobachtungen zur griechisch-römischen und altchinesischen Geschichtsschreibung, "Saeculum” 1997, 48.

Mutschler F. H., Tacitus und Sima Qian: Persönliche Erfahrung und historiographische Perspektive, „Philologus” 2007, 151.

Rome and China. Comparative Perspectives on Ancient World Empires, ed. W. Scheidel, Oxford 2009.

Rosenblitt J. A., Rome and North Corea: Totalitarian Questions, „Greece and Rome” 2012, 59.

Smila V., Why America is not a new Rome, Cambridge-Massachusetts-London 2010.

Tanner J., Ancient Greece, Early China: Sino-Hellenic Studies and Comparative Approaches to the Classical World: A Review Article, „Journal of Hellenic Studies" 2009.

The Dynamics of Ancient Empires: State Power from Assyria to Byzantium, ed. I. Morris, W. Scheidel, Oxford 2010.

The Oxford Handbook of the State in the Ancient Near East and Mediterranean, ed. P. F. Bang, W. Scheidel, Oxford 2013.

Vasunia P., The Comparative Studies of Empires, „Journal of Roman Studies" 2011, 101. 